\title{
The three phases of transforming a project- based IT company into a lean and design-led digital service provider
}

\author{
Kuula S., Haapasalo H., Kosonen, J-M.
}

\begin{abstract}
Digital transformation requires a continuous review of value creation, value capture, and resourcing. It is not reasonable to deliver only relieving service based on customer requests or suppliers pre-defined offering. The co-creational value definition has to be specified in the encountering process. In this paper we define a systematical service design concept to co-creational and cross-functional knowledge-intensive business service development. We have aligned the service deliverables (value creation) and customer needs (value capture) by utilizing design thinking in the value co-creational servicedominant logic framework. This case study falls into Design Science Research Methodology (DSRM), following the logic of constructive research, adapting the role of the researcher from Action Design Research (ADR) wherein created framework is tested and further developed in a real KIBS environment over several years. Our case company provides ICT services for customers across all industries. Main findings from the validation of the framework we can summarize: 1) Co-creation with the client in a design sprint format (agile co-creation and rapid prototyping), 2) Within all of these analysed cases supplier was able to use the learned customers' business insight into expanding its offering to other (digital) services (continuum), 3) Making sure the right things were developed, the business risk was better controlled (doing the wrong things right is not enough for avoiding reclamations) and 4) Ensuring value in delivery was positioning supplier better, from relieving services to enabling services.
\end{abstract}

Index Terms - design thinking, co-creation, digitalization, service design, knowledge-intensive business services

\section{INTRODUCTION}

$\mathrm{T}$ HE business landscape in the digital era is service-oriented, genuinely global, and in constant change. Companies are reimagining their business digitally, trying to radically improve their competitiveness while exploring the underlying changes in customer needs. Genuinely new, service-dominant business models are created. Every company is going through digital transformation, but a prevailing misconception is that it is just something that companies do with technology. Instead, digital transformation is more about how technology changes the customer expectations and business processes, thus constantly alters the business environment [1].

Value creation provides legitimacy for the company's existence and the basis for its business [2]. The focus of the commercialization of the offering should be on the ability to understand and support the value creation process of the customers. The service deliverables (value creation)

- Kuula S. a CEO of Enfo Oyj, a Nordic SW system integrator, and is a researcher with University of Oulu, Industrial Engineering and Management, P.O. Box 4610, FIN-90014 University of Oulu, FINLAND. E-mail: seppo.kuula@enfogroup.com

- Haapasalo H. is a professor with University of Oulu, Industrial Engineering and Management, P.O. Box 4610, FIN-90014 University of Oulu, FINLAND. E-mail: harri.haapasalo@oulu.fi

- Kosonen, J-M. is a Director of Design with Siili Solutions Oyj, and studied with Aalto University, School of Business, International Design Business Management. P.O. Box PL 11000, 00076 FIN-Aalto, FINLAND. E-mail: juha-matti.kosonen@siili.com and customer needs (value capture) can be aligned by utilizing design thinking (DT) in a value co-creational servicedominant logic (SDL) framework. SDL gives a sound foundational framework for understanding value co-creation and dynamic resource integration, underlining the collaborative nature of value creation [3], [4], [5], [6], [7] and DT is a widely accepted human-centric management practice that advantages the design tools in business development [8]. A combination of these two practices provides the systematical framework for continuous, systematical, and cocreative service design, taking account of technology, business, and human behavior.

The main aim of this paper is to describe a systematical service design approach for cross-functional knowledgeintensive business service (KIBS) development in a constantly altering business environment wherein digitalization is driving companies towards service-dominant business models. This research falls into Design Science Research Methodology (DSRM) [9]. Our development work has followed the logic of constructive research, adapting the role of the researcher from Action Design Research (ADR) wherein created framework is tested and further developed in a real KIBS environment over several years. Our case company provides ICT services for customers across all industries. 


\section{SERVICE-DOMINANT LOGIC AND DESIGN THINKING}

The most significant difference between industrializationdriven goods-dominant logic (GDL) and globalizationdriven SDL can be seen in the definition of value (co-creation) and the exchange (integration) of resources. In SDL all actors, including the customer, use their available resources to co-create value as integrators, and this value is perceived by the customer on the basis of value-in-context [10].

SDL implies that value is co-created with the customer rather than embedded in output. The objective of the supplier in a co-creational relationship is to customize the offering in achieving participation in the customer value creation processes. Competitive advantages are based on core competencies like knowledge, skills, and processes. [11], [12]. In SDL, the value is iteratively co-created with the customer, and competitive edge is created progressively through constantly improving the service experience [13].

Through multiple perspectives, service design should synthetize and creatively transform the collective knowledge through new service or product concepts. This approach is generally called design thinking (DT) [8], [14], [15]. DT combines a deep end-user experience, systems thinking, iterative rapid prototyping, and multi-stakeholder feedback [8]. DT is focused on gaining an understanding of an area of human experience, aiming to transform this integrated knowledge into new solutions, taking account of the angles of value, creation, and capture [8], [14], [15]. DT is a human-centric management practice that advantages the service design practices in business development.

DT is not a scientific theory but more like an applied mindset and framework: be curious, try things, reframe problems, embrace the process, and collaborate [16]. DT encourages learning by doing in desired solution creation. The difference between conventional service design and DT is that DT not only explores the value creation space but also explores value capture in the business model [17]. Research ends in insight, creation ends in ideas, and delivery ends in reality. In comparison with DT, agile development and Lean Startup have some strong parallels, like user-centricity, iterative learning, and extensive team communication. [6], [7].

Double diamond-model is another way to describe the DT process, and it puts more focus on the problems space in its description. The diamond shape aims to visualize the thinking modes, divergent and convergent thinking, along the design process (Emphaty, Define, Ideate, Prototype and Test). [18]. Divergent DT is used first for the first and the third phases before reaching a convergent out-come. This approach prevents one of the most common mistakes: solving the wrong problem. Practical design methodslike user diaries, journey mapping, and character profiles-are used through all phases.

\section{Methodology}

DSRM requires the creation of an innovative, purposeful construct for a special problem domain, which must be evaluated to ensure its utility for the specified problem [9] (in this research Service design and value co-creation framework). According DRSM the results of the research need to be presented effectively both to technology-oriented and management-oriented audiences.

Our development follows the logic of constructive research [18], adapting the role of the researcher from ADR [20]. Building theory with the aid of case studies is a research strategy that involves using one or more cases to create constructs, propositions and/or midrange theory from case-based, empirical evidence. The constructive step-wise process has been adapted from Kasanen et al. [19]. The problem was originated in the business development process whereby the company was transformed from resource provider into an agile digital solution provider. In this process the offering was iteratively developed in order to respond to the increasing "cloud-based shadow IT" need where the supplier creates a full stack (from data management through application to usability) solution to the customer's specific business need. The studied service design solution was developed using the iterative action research process over years, and the validation was performed through real-life case studies.

The construction process had three main iterations in order to find the solid state of the co-creational service design process. The first approach was based on the strategical planning process (in 2014) as an answer to creative offering development alongside iterative business development. The solution was named the Digihub, reflecting the nature of close collaboration between the different actors and disciplines during the solution creation. The second iteration was seeking more formalized processes for managing the creativity and a repeatable solution for demonstrating the outcome Design through prototyping. The third and final iteration (in 2016), was combining business design and Service design and value creation together under a DT framework and co-creational delivery management. This solution is defined in detail as an outcome of the framework development, assuming applicability generally in KIBS business development processes. Finally, we have validated and evaluated the "service design and value cocreation framework" (see fig. 3 later). The demonstration of the solution frame-work is done in three real-life cases, applying the ADR [20] (Table I later). Problem Formulation Empathize, Define, Ideate, Test and Prototype and finally formalization of the learning as typical for DSRM.

\section{Constructing the SOlution}

Our case organization was founded in 2005 and provides data analytics, and design and technology services to companies across industries. Originally, the company was a coding resource provider, but a pull-driven offering development process expanded the competence portfolio, first towards data management and then towards design services (see siili.com).

In Siili's organisation service design usually led to digital service creation, where Siili was having hundreds of UX-designers, coders and data management specialists supporting the solution development. The ratio between 
service designers and developers (incl. UX and data) was about 1:30. Technologically agnostic approach is important for co-creative solution development partner, which is addressing to design - related challenge; can digital service creator avoid leading a customer towards digital solutions. In our study two out of three cases were finding a solution where the digital development was not the solution.

\subsection{The first cycle: The Digihub}

This research started in the beginning of 2014 as a response to a strategic need to focus in ensuring the delivered solutions truly created value for customers, simultaneously transitioning the company's service development from opportunity management (push) to account management (pull). The company had identified the need to strengthen its design capabilities, especially expanding competences from usability to business and service designs. Business design expertise was required for being able to understand customers' business processes, opportunities, and value capture, and service design expertise was required for facilitating the continuous problem and solution definition in the value proposition. The tasks of the named strategy project were i) to (continuously) identify the business problems and business processes with the customer, ii) to eliminate waste and focus on value creative actions, and iii) to control the process and validate value co-creation by measuring the key parameters.

The company's business development organization assessed this question from two directions - business architecture (processes and information flow) and service design - and found its capabilities to understand its customers' business and processes very limited. In this case, it was possible to expand the enterprise architecture and business process expertise over existing information system architecture and information management expertise, but there was no service design competence in the organization. The company began exploring possible acquisition targets with modern service design competence and formed an internal project for generating a model for developing the co-creationalservice design process. The results of this iteration, executed between 2014 and summer 2015 and the end result of the first development round was called the Digihub (Fig. 1).

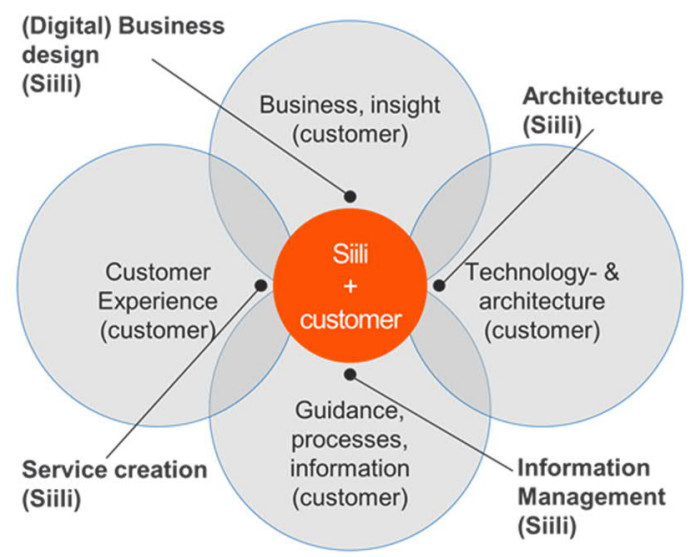

Fig. 1. The result of the first development round in developing a systematical service design approach for cross-functional knowledge-intensive business service (KIBS) development. The Digihub's 2015 model of the
Three different managerial decisions were based on this

1. The company acquired another company with a strong service design background and a moderate business design background-at the end of 2014, because of lacking service design competence.

2. The company's service development organization, analysed and started to apply the Lean Startup approach to defining an iterative and co-creational collaboration process.

3. The company redefined its offering in 2015 to include service innovation as a bootstrap among the system architecture, and it created a new process for customer collaboration and service management in the same year.

\subsection{The second cycle: Designing through prototyping}

The Digihub setup did not always meet the desired outcome, being highly dependent on the development resources. In particular, the customer's business organization was not always committed neither co-creational approach, nor the prioritization of continuous development. The second iteration, originated in the H1/2015 strategy review, focused on definition of the iterative problem and demonstrating the outcomes through prototyping. The idea was to either prove the value of the outcome in an early phase or pivot the development before incurring significant costs. The firm's technology expertise, together with user-experience design and prototyping practices was strong, but its business design skills were limited. The Lean Startup process-related rapid prototyping was seen as a solution for facilitating business development.

This approach was challenged again at the end of 2015, mainly because of an insecure business design approach wherein business understanding did not reach the exploration of value capture. The problem space was also not well explored, and testing was based on conventional user group questions. Business process knowledge, together with information management expertise, connected the company to the customer's business organization, but collaboration in business design very rarely occurred. Anyhow, this iteration strengthened the repeatability of the service design process through having defined design roles and standardizing the used tools. Prototyping was also seen as an extremely valuable part of service design (Fig. 2).

The synthesis managerial decisions after this cycle were:

1. We had to have commitment from customer's business organization co-creation, as the original scope typically changed during the process.

2. Agile rapid prototyping was seen as a solution for facilitating business development in the customer side to reveal the real need also for the customer.

3. More effort was needed for exploring the real business related needs of customer. iteration: 


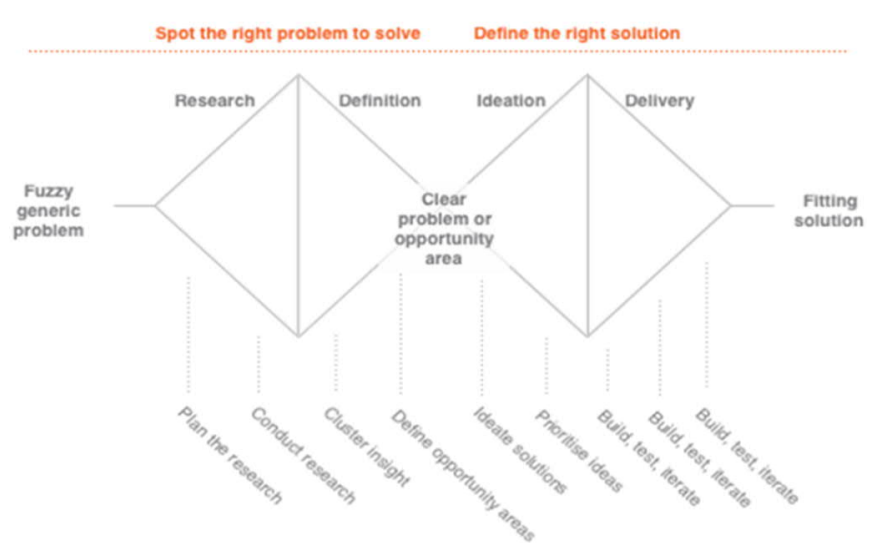

Fig. 2. The result of the second development round - Designing through prototyping. The case company's processes for continuous and co-creative service desian in 2017.

\subsection{The third cycle: Service design and value co- creation}

The third iteration originated in the 2016 and was executed in between 2016 and summer 2017. The first author, together with the company's design organization, had studied DT and found it to be a rallying point for service design and business design. Based on this finding, the original research question for the third round considered how to combine DT with digital service co-creation, considering all actors. By combining DT with the co-creational service development process, aligning the vision and short-term target setting with continuous busi-ness model development allowed the company to continuously focus on the value-creative KIBS.

In this model the conceptual service design process follows DT in the exploration of the prob-lem space, and the Lean Startup circle, build-measure-learn, is used to define and prototype the solution. Prototypes are used for collecting real-world feedback and learning about the solution definition with continuous improvement. When the solution is proven to meet the expectations, the final solution is developed with agile methods through the MVP (Minimum Viable Product). In the MVP phase, the solution and development process have to pass final acceptance from both value creational and value capture angles. Within this process, our goal is to is start from the customer's strategy and service vision, aligning value creational activities with early-stage ex-periences, evaluating alternative problem spaces, creating prototypes for iterative testing, eval-uating ideas and concepts for solutions, and redefining the goal as a continuous process.

As described above, the building of organizational competence and the intervention in it were done in a real business environment. The design process and research results were evaluated in confirmatory workshops in spring 2017.
Based on this development, we constructed the generic cocreational- and DT-inspired framework for continuous and iterative service design needs that is shown in Fig. 3.

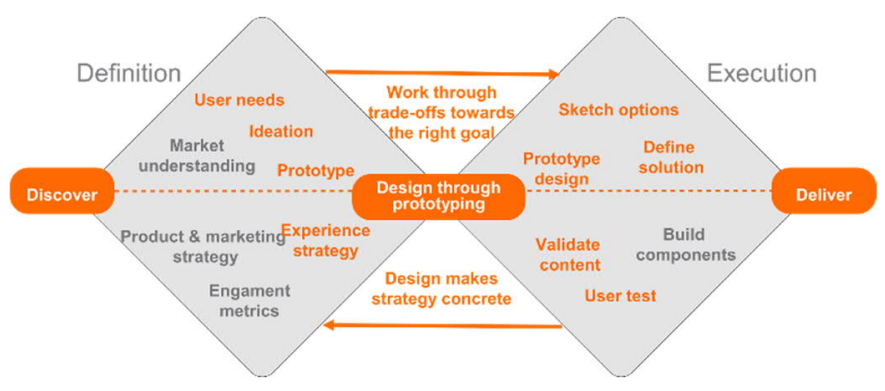

Fig. 3. The result of the third development round - Service design and value co-creation. The case company's processes for continuous and co-creative service design in 2017.

The synthesis managerial decisions after this cycle were:

1. In order to systematize our offering, we needed to combine DT with digital ser-vice co-creation, considering all actors.

2. We had to create structure for Minimum Viable Product (MVP) to structure our offer to be more effective.

3. To understand what real customer needs are instead of the requirements, we need to also understand customer's business model and service vision.

\subsection{Evaluating the solution}

In order to display proof of the validity of the DT-inspired co-creational service design the case company has applied the processes for continuous and co-creative service design in several service deliveries. We have documented three real-life cases for the validation.

In sense of weak market test [19] all three cases proved to be valuable while customers implemented the "prototype" of service delivery (Table I). In the end of first case, the project team came up with a new service strategy and concepts regarding how to pursue competitive advantage by serving doctors in a more meaningful manner and also came up with a new business concept that was later on piloted also with a private hospital in order to develop the concept further. In the second case we can say that the DTdriven concepting process was proved valid as the insurance product had a high sales rate from the launch and high customer engagement over an extended period of time. In the third case the storyboard served as a tool that communicated the customer-driven vision of the company's future services and was used as a guiding tool for the service development activities. The vision was also coupled with a mock-up prototype of the envisioned digital service. The mock-up prototype made the story more tangible and helped the stakeholders to get a better grasp of the vision. 
TABLE I.

THE DEMONSTRATION OF THE SOLUTION FRAMEWORK IS DONE IN CASE COMPANYS THREE TYPICAL REAL-LIFE BUSINESS CASES

\begin{tabular}{|l|l|l|l|l|l|}
\hline Case & \multicolumn{1}{|c|}{ Empathize } & \multicolumn{1}{|c|}{ Define } & \multicolumn{1}{|c|}{ Ideate } & \multicolumn{1}{|c|}{ Test } & \multicolumn{1}{|c|}{ Prototype } \\
\hline $\begin{array}{l}\text { Case 1. Service Innovation } \\
\text { for defending market } \\
\text { (pharmaceutical) }\end{array}$ & $\begin{array}{l}\text { Deep contextual inter- } \\
\text { views (qualitative) }\end{array}$ & $\begin{array}{l}\text { Better use of the } \\
\text { existing infor- } \\
\text { mation }\end{array}$ & $\begin{array}{l}\text { Service blue- } \\
\text { prints }\end{array}$ & $\begin{array}{l}\text { Conceptual } \\
\text { solutions for } \\
\text { doctors }\end{array}$ & $\begin{array}{l}\text { New concept and } \\
\text { business model, pi- } \\
\text { loted in hospital }\end{array}$ \\
\hline $\begin{array}{l}\text { Case 2. Validating the new } \\
\text { business model in whole- } \\
\text { sale (insurance) }\end{array}$ & $\begin{array}{l}\text { Contextual interviews } \\
\text { (quantitative) }\end{array}$ & $\begin{array}{l}\text { New structure for } \\
\text { the existing in } \\
\text { product }\end{array}$ & $\begin{array}{l}\text { Service value } \\
\text { proposition can- } \\
\text { vas }\end{array}$ & $\begin{array}{l}\text { Public pilot } \\
\text { with the real } \\
\text { customers }\end{array}$ & $\begin{array}{l}\text { Structured te- } \\
\text { lephone interview }\end{array}$ \\
\hline $\begin{array}{l}\text { Case 3. A service vision } \\
\text { for a manufacturing com- } \\
\text { pany }\end{array}$ & $\begin{array}{l}\text { Creating different cus- } \\
\text { tomer profiles and per- } \\
\text { sonas. Customer journey }\end{array}$ & $\begin{array}{l}\text { Compelling digital } \\
\text { services against } \\
\text { new competitors }\end{array}$ & $\begin{array}{l}\text { Brainwriting } \\
\text { and crazy eights } \\
\text { - methods }\end{array}$ & $\begin{array}{l}\text { Service } \\
\text { walkthrough } \\
\text { sessions }\end{array}$ & $\begin{array}{l}\text { Semi-structured fol- } \\
\text { low-up interviews }\end{array}$ \\
\hline
\end{tabular}

Our research sheds light on demystifying the whole knowledge-intensive business service delivery, by aiming to systematize the delivery processes. Through the systematization we aim to contribute to the search for business efficiency. Searching for customer satisfaction, with-out systematization - with any means possible, easily ends up in waste and variation in quality. We have created and tested, at least on rough level, the descripted co-creational service design -model, (naturally we have more detailed model for the case company purposes). Features following all three original iterations, however noted in ex-post analysis, were quite easy to summarize:

- Co-creation with the client in a design sprint format (agile co-creation and rapid prototyping).

- Within all of these cases supplier was able to use the learned customers' business insight into expanding its offering to other (digital) services (continuum).

- Making sure the right things were developed, the business risk was better controlled (doing the things right is not enough for avoiding reclamations).

- Ensuring value in delivery was positioning supplier better, from relieving services to enabling services.

During validation we discovered that one of the most important pinpoints, in an organizational sense, is the learning itself. The Double Diamond certainly works as a process platform in the DT process, being the backend for a continuous, deliverable definition process.

Case company's solution delivery capability iteratively increased over the years while studied the phenomenon. The transformation of the offering transformed the whole company, from customer collaboration to delivery processes. The company had success in its business through the transformation, which, together with the continuous growth, brought additional pressure to development. The transformation had to be rooted in culture, and thus, it required a long time. Three major iterations were required before the approach found a repeatable form. DT and cocreation were seamlessly integrated into case company's service delivery process, providing more efficiency and effectiveness, and in particular, the expected continuous deliv-erable definition. In the nature of design thinking, the offering and delivery development work has continued in the case company after these three rounds described in this research.

\section{CONCLUSION}

DT is a mindset and framework kind of management practice, advancing the service design practices in business development. It has roots inside the design process, where the solutions are human-centric and creative. DT takes account of not only value creational perspectives but also value capture-related facts.

In service design, it covers the iterative process through several phases, from inspiration, through ideation, reflection, prototyping, and testing, and finally on to implementation. How-ever, business management should aim for the repetition and systematization of services; even customers require customization. A recent study on portfolio management for service and product offerings [21], [22] led us on an avenue of developing KIBS deliveries in order to clarify the value creation and increase the cost efficiency, and thus the profitability. With this point of origin, we have created a systematic service design approach for cross-functional ser-vice development. We have utilized three iteration cycles, with a constructive approach, in order to develop the model. As part of the constructive process, we also tested the solution in real-life business cases in order to validate our approach.

Based on our study, this DT-inspired co-creational solution development approach can serve as a foundation for service development. The model gives an understandable framework for all of the stakeholders involved, providing clarity, common understanding, and common lan-guage through the process. With the help of the model all of the stakeholders are able to op-erate smart problem-solving process, and thus achieve better outcomes in their co-creation ac-tivities. The model also reduces the resource risks that are included in development projects, such as building a solution that has not been validated with the end-customers.

The Double Diamond model roots the activities in a level that can be utilized as a managerial process model for communicating service development between developers and as a customer co-creation process for defining the com-

mercial deliverables. In our study the model worked in the 
case of KIBSs; however, more lessons are required from different types of services. Of course, the detailed level descriptions differ with different types of services. Therefore, the organization-specific learning process of service design offers significant learning and devel-opment opportunities, which is one of the following research avenues for our future studies.

\section{ACKNOWLEDGMENT}

The authors wish to thank Siili Solutions Oyj for acting as a case company in our study providing all necessary materials for our study. The corresponding athor of this paper is professor H. Haapasalo.

\section{REFERENCES}

[1] C. Meinel, L. Leifer and H. Plattner, Design Thinking. Berlin, Heidelberg, Springer. 2011.

[2] M.E. Porter, Competitive Advantage. Free Press. 1985.

[3] S.L. Vargo and R.F. Lusch, "Evolving to a New Dominant Logic for Marketing," Journal of marketing, vol. 68, no. 1, pp. 1-17. 2004. doi: 10.1509 jmkg.68.1.1.24036.

[4] A.F. Payne, K. Storbacka and P. Frow, "Managing the Co-Creation of Value," Journal of the academy of marketing science, vol. 36, no. 1, pp. 83-96. 2008. doi: 10.1007/s11747-007-0070-0

[5] C.M. Christensen. The Innovator's Dilemma. 1. Collins Business Essential ed. New York, NY: Harper Business. 2010.

[6] E. Ries, The Lean Startup: How Today's Entrepreneurs Use Continuous Innovation to Create Radically Successful Businesses. 1st ed. New York: Crown Business. 2011.

[7] S.G. Blank, The Four Steps to the Epiphany: Successful Strategies for Products That Win. Fifth edition. California. 2013.

[8] T. Brown, "Design Thinking," Harvard business review, vol. 86, no. 6, pp. 84-94. 2008.

[9] K. Peffers, T. Tuunanen, M.A. Rothenberger and S. Chatterjee, "A Design Science Research Methodology for Information Systems Research," Journal of Management Information Systems, vol 24, no 3, pp. 45-77. 2007. doi: 10.2753 MIS0742-1222240302

[10] S. Kuula, H. Haapasalo and A. Tolonen, "Cost-efficient Co-creation of Knowledge Intensive Business Services," Service business 12, no. 4, pp. 779-808. 2018. doi: 10.1007/s11628-018-0380-y

[11] S.L. Vargo, "On Marketing Theory and Service-Dominant Logic: Connecting Some Dots," Marketing Theory, vol. 11, no. 1, pp. 3-8. 2011. doi:10.1177/1470593110393715.

[12] S.L. Vargo and R.F. Lusch, "Service-Dominant Logic: Continuing the Evolution," Journal of the academy of marketing science, vol. 36, no. 1, pp. 1-10. 2008. doi:10.1007/s11747-007-0069-6

[13] E. van Bommel, D. Edelman and K. Ungerman, Digitizing the Consumer Decision Journey. McKinsey \& Company. 2014.

[14] D. Dunne and R. Martin, "Design Thinking and How It Will Change Management Education," Academy of management learning and education, vol. 5, no. 4, pp. 512-523. 2006. doi: 10.5465 amle. 2006.23473212

[15] T. Lindberg, C. Noweski and C. Meinel, Design Thinking: Zur Entwicklung eines explorativen Forschungsansatzes zu einem "uber- professionellen Modell. Neuwerk, Zeitschrift f"ur Designwissenschaft, pp. 47-54. 2009.

[16] H. Plattner, C. Meinel and L. Leifer, Design thinking: understand, improve, apply. Understanding innovation. Berlin; Heidelberg: Springer-Verlag. pp. xiv-xvi. 2011.

[17] M. Kleinsmann, R. Valkenburg and J. Sluijs, "Capturing the Value of Design Thinking in Different Innovation Practices," International journal of design, vol. 11, no. 2, pp. 25-40. 2017.

[18] British Design Council Eleven lessons. A Study of the Design Process. www.designcouncil.org.uk. Retrieved 9 November 2016. 2016.

[19] E. Kasanen, K. Lukka and A. Siitonen, "The Constructive Approach in Management Accounting Research," Journal of management accounting research, vol. 5, pp. 243-264. 1993.

[20] M.K. Sein, O. Henfridsson, S. Purao, M. Rossi and R. Lindgren, "Action Design Research," MIS quarterly, vol. 35, no. 1, pp. 3756. 2011. doi: $10.2307 / 23043488$

[21] A. Tolonen, J. Harkonen and H. Haapasalo, Product Portfolio management-Governance for Commercial and Technical Portfolios over Life Cycle. Technology and investment, vol. 5, no. 4, pp. 173-183. 2014. doi:10.4236/ti.2014.54016

[22] A. Tolonen, J. Harkonen, M. Verkasalo and H. Haapasalo, "Product portfolio Management Process over Horizontal and Vertical Portfolios," International journal of product lifecycle management, vol. 8(3, pp. 189-215. 2015. doi:10.1504/JJPLM.2015.074132

S. Kuula is an experienced business executive with versatile and multicultural background in leadership at the complex technology and professional services environment. Career is significantly focused in the value-based commercialization of Professional Services, and International Sales management. Believing in lifelong learning, holding three academic degrees; M.Sc. (Ind. Eng. \& Mgmt), B.Sc. (Eng.), and eMBA, conducting Doctoral research about Service Dominant Logic in Professional Services context at Oulu University. Currently serving as Chief Executive Officer in Enfogroup. Nominated as the Finnish Software Entrepreneur of the Year 2014 (The Finnish Software Entrepreneurs Association) for the entrepreneurial leadership.

H. Haapasalo has been Professor in Product Management 20 years in the Industrial Engineering and Management at the University of Oulu. He has a Doctors degree in Technology Management and also a Master's degree in Economics and Business Administration. He has research interests in business management, product management and also in management of production processes. The list of publications covers more than 300 international scientific publications. He has been as chair and committee member in organizing numerous international conferences, and has been as a reviewer and belongs to the editorial board for several international scientific journals.

$\mathbf{J}-\mathbf{M}$. Kosonen is a strategic designer and a design leader. He has been working in design and technology consultancies for more than ten years, helping companies to discover, define and implement new products, strategies, and services. In addition to practice, Juha-Matti has a keen interests towards design theory and academia. Juha-Matti holds a Master of Science degree from Aalto University's International Design Business Management -program. 